\title{
Environmental management and the organization of labor rationing in industrialized countries at the corporate level
}

\author{
Irina Omelchenko ${ }^{1}$, Oleg Dozortzev ${ }^{1}$, Marina Danilina ${ }^{1,2,3,}$, , Alexander Vas'kov', \\ Ekaterina Safonova ${ }^{1}$, Alexander Safonov ${ }^{1}$ \\ ${ }^{1}$ Research Institute VNII of Labor, Ministry of Labour of Russia, Zemlyanoy Val, 34, 105064 \\ Moscow, Russia \\ ${ }^{2}$ Finance University under the Government of the Russian Federation, Leningradsky prosp., 49, \\ 125993 Moscow, Russia \\ ${ }^{3}$ Russian Economic University, Stremyanny per., 36, 117997 Moscow, Russia
}

\begin{abstract}
Approaches to solving environmental problems should be developed taking into account the concept of the "triangle of sustainable development". The sides of this triangle are not only "ecology" and "economics" and their interactions, but also "social factors", taking into account direct and reverse relationships. The implementation of active environmental management by companies and an integrated approach to environmental protection require the involvement of personnel at all levels of work to address these issues, motivation of personnel, and the creation of conditions for advanced training in a new area. Under these conditions, the issue of labor rationing is also of particular relevance. Based on content analysis, the authors investigate various systems of developed countries.
\end{abstract}

\section{Introduction}

In order for the targets set during the development of the company's environmental strategy to be realized, the company must have a corporate environmental management system. The formation of the corporate environmental management system should be carried out after the preparation of the initial environmental review, taking into account the analysis of the internal and external environment of the company's environmental marketing strategy.

After the creation of the corporate environmental management system, a new stage is being implemented - personnel training. The training is achieved by the employees of the enterprise understanding the importance of the environmental policy of the organization and the acquisition of the required competencies.

Further, the development of an operational action plan for environmental protection, operational control and monitoring of its implementation, audit of the validity of target and planned environmental indicators of the company, the effectiveness and validity of its environmental protection measures are carried out.

Corresponding author: marinadanilina@yandex.ru 
The implementation of active environmental management by companies and an integrated approach to environmental protection require the involvement of personnel at all levels of work in solving these issues, motivation of personnel, and the creation of conditions for advanced training in a new area.

According to the calculations of leading insurance companies, up to half of environmental accidents occur through human fault, which is due to the fact that: 1) environmental issues are often interpreted as relevant only for a narrow circle of specialists and departments of the enterprise, and not as a matter of all employees; 2) this problem is considered only as technical or technological, without taking into account the role of the human factor; 3 ) the burden on the environment for an employee at one workplace, as a rule, is not perceptible, although from the standpoint of the ecological balance of the enterprise they can be very significant; 4) often the negative environmental effects of the administrative departments of the enterprise and production are not taken into account, including because the media put pressure on the company due to its emissions into the environment or generated waste, but without taking into account its overall environmental impact.

The preservation of the technocratic method of management at the enterprises and the narrowness in assessing environmental problems overshadow the importance of personnel management in resolving them, but it is on the shoulders of the company's personnel that the responsible task of transforming the company's strategic environmental goals into results recognized by society lies.

It is the personnel who, by their environmentally conscious behavior, are in no small measure able to serve the progressive development of the company. Employee behavior in relation to environmental protection can be contradictory and simply passive. It is necessary to take into account the underdevelopment of the environmental consciousness of workers, including the management apparatus, the complexity of motivation.

\section{Materials and methods}

Approaches to solving environmental problems should be developed taking into account the concept of the "triangle of sustainable development". The sides of this triangle are not only "ecology" and "economics" and their interactions, but also "social factors", taking into account direct and reverse relationships. Social issues within the framework of the concept of corporate environmental management and sustainable development are present in an expanded form, including ensuring the quality of life and jobs, the formation of a relevant corporate culture, as well as democracy in environmental decision-making.

A special focus is on examining the impact of firms' implementation of environmentally sustainable marketing strategies on social issues affecting employment. A company pursuing an active environmental policy is faced with the need to radically change the personal management system, because employees and their behavior, and not only technologies, are carriers of environmental progress.

Personnel management, regardless of the corporate environmental management model used on it, covers the determination of the need for personnel, taking into account the new environmental objectives of the company, the selection of appropriate personnel and their placement; advanced training, retraining and staff growth; assessment of personnel performance; personnel management based on the development of an appropriate leadership style and corporate culture; stimulating and motivating environmentally relevant staff behavior.

When starting to determine the need for environmentally trained personnel, the management of the enterprise and its personnel services should take into account that these 
needs differ not only depending on the size, industry, technical and technological level of the enterprise and similar factors, but also on the adopted model of corporate environmental management.

For an enterprise that implements an additive approach to corporate environmental management, personnel problems are solved mainly through the creation of new jobs, recruiting additional personnel, and attracting outside specialists. Within the framework of an integrated approach to corporate environmental management, it is more important to retrain and improve the qualifications of the company's own personnel. Also an important point is labor rationing.

In this article we consider the different approaches to labor rationing that are common in developed countries. Decentralization in the development of labor standards in a market economy has led to the strengthening of the principle of democracy in enterprise management, which ensures the alignment of the most important social and labor interests of the employer and the employee. In Germany, in particular, this principle was confirmed by the activities of trade unions, whose status is enshrined in law.

The right of the works council to participate in the management of the enterprise affects the following aspects:

- working hours (setting the beginning and end of the working day, etc.));

-salary;

- determination of technical means of control over the behavior and productivity of workers;

- defining the wage policy;

- Establishing an estimate for a bonus form of wages;

- the issue of submitting proposals for the organization of production processes, etc.

Consequently, a wide range of tasks of the works council gives it the opportunity to control almost all spheres of internal and external activities of the enterprise, including labor rationing.

The participation of employees in the management of the company occurs jointly with the trade union through a labor manager who is a member of the company's board. The labor manager has the same rights as other members of the board of directors and is responsible for achieving the goals, economic policy and interests of the company. In addition to other areas of company economic policy, he also deals with staffing, social issues and wages.

A lot of research carried out by the European Association of National Productivity Centers and the MTM Association, as well as entrepreneurs from most of the developed countries of the world, has expanded the scope of labor standards in all industries in recent years. A prerequisite for such research is the need to constantly reduce production costs and, on this basis, increase competitiveness in the domestic and foreign markets.

Experience shows that in developed foreign countries, the calculation of norms is carried out on the basis of microelement standards. For example, the above PMTS method for improving workflows was developed by American experts Frank and Lillian Gilbert. The advantage of this method is the high level of detail in workflows. When applying it, all the movements necessary to perform the work in question are determined and analyzed. Another advantage of PMTS is the ability to use it to plan jobs with any accuracy before the start of the main set of job rationing.

The PMTS system was originally used primarily to study and improve labor productivity. But almost immediately, a more modern version was developed, which was called methods-time measurement (MTM). This system was called microelement rationing, which provides for the division of any labor actions into simple ones, movements, from which manual movements are modeled and the time spent on their implementation is calculated. 
Microelement rationing became widespread in the late 1940s and early 1950s, first in the United States, later this system became popular in Germany, France, Japan and other countries. At the moment, there are many variants of trace element systems in the world, which are also used in the process of normalizing activities associated with the intellectual work of a person.

One of the first forms of this system is the factorial method, in which motion is analyzed, assuming a significantly lower level of complexity and accuracy, i.e., the original elemental motion of the PMTS system was included in a larger module. For example, the "removal" module consists of two simple movements, from which the actions of an employee are formed, who pulls out and receives the object of labor, and the "installation" module consists of the elements "replacement" and "setting a given situation". Such a simple approach to the implementation of the MTM system is called "compaction" or "condensation" in industrial engineering.

The most widely used in the United States and Western Europe was the system created in the 40s by Maynard and Schwab called the "system for studying the methods and timing of movements" (abbreviated English name MTM). Its development was subsidized by the Westinghouse Electric Corporation. In the United States, a company was founded that was engaged in the development and application of this system in enterprises, as well as the MTM society, uniting theorists and practitioners.

To establish the required time expenditure with the help of the MTM system, the standardized work must be divided into the simplest labor movements and each of them must be carefully studied. At the same time, the task is always posed - to reduce the number of movements and their duration, as well as with the help of various devices to reduce the degree of accuracy and accuracy of movement that is required from the worker. The speed of work depends on these factors (the more accuracy is required, the slower the movement is performed). By reducing the number of movements required to perform operations, and speeding them up, the normalizer achieves an increase in daily output with the same number of labor movements.

Thus, with a decrease in the number of labor movements spent on performing one operation by $25 \%$, the output increases by $25 \%$, and the number of movements during the whole working day remains unchanged. The capitalist won by using the MTM system, but the worker did not lose anything: he makes exactly the same number of movements as before. The worker cannot protest. The capitalist has the same right to rationalize labor practices as the technological process. Everything seems to be quite well.

But in the MTM system, as will be shown below, there are great possibilities for the hidden intensification of labor under the guise of eliminating unnecessary movements and facilitating the necessary ones. This is, first of all, a high tempo, hidden in the norms of the time of movements, as well as the compilation of the norm of time from the minimum periods of time provided for each movement, studied separately from adjacent movements in favorable conditions of execution.

The entrepreneur can, without any arbitrariness, only on a "scientific" basis, demand from the workers, after reducing the number of movements spent on the performance of each operation, also to increase the pace of work, since the remaining necessary movements are "facilitated".

This intensification of labor is especially beneficial for the capitalists in that it can be achieved without raising wages: the worker is "scientifically" told that he is putting as much physical and mental energy into work as before. The entrepreneur, having spent his money on the use of the MTM system, only made sure that this energy was more expediently directed.

The MTM system is used to develop standards in various industries and construction. When developing standards for techniques using microelement standards, as well as when 
developing them by the method of timing, much attention is paid to the preliminary study of the work that is planned to be covered by the standards, the nature of production operations, the characteristics of equipment, tools and materials, the layout of the workplace, the qualifications of workers and their development, etc. As a result of this study, the elements for which standards should be developed are determined.

Then a detailed description of each element is drawn up, indicating all the conditions that affect the time of its implementation. When collecting this information, rationers are asked to follow the rule: "it is better to collect unnecessary information than not have the necessary information."

Having the necessary information, the standardizer proceeds to dismember the techniques into microelements in order to identify the necessary movements and select the appropriate microelement standards according to the MTM tables. The normalizer carefully checks the correctness of this analysis at the workplace, in order to leave only the necessary movements and those of their varieties that require the least time.

Then a detailed description of each element is drawn up, indicating all the conditions that affect the time of its implementation. When collecting this information, rationers are asked to follow the rule: "it is better to collect unnecessary information than not have the necessary information."

Having the necessary information, the standardizer proceeds to dismember the techniques into microelements in order to identify the necessary movements and select the appropriate microelement standards according to the MTM tables. The normalizer carefully checks the correctness of this analysis at the workplace, in order to leave only the necessary movements and those of their varieties that require the least time.

Having compiled these standards, the standardizer checks them using timekeeping. For this, the actually performed work is divided into methods and, according to the standards, a trial time rate is made. Then, regular time observations are carried out with an assessment of the pace of work in order to compare the actual time with the norm, drawn up according to the standards.

With significant differences (over 5\%) between the duration of receptions established by the timing, and the norms of receptions according to the MTM data, the reasons for this discrepancy are clarified. If the actual duration is longer than the standard, it is considered a sign that workers are using less rational practices than those prescribed by the standards, or working at a too slow pace.

The results of this test are used to improve workplace organization, train workers in a standard working method, or replace them with more skillful and hardy workers.

If the standards are higher than the actual time, opportunities to save movements are identified to increase the stringency of the standards.

The standard time of receptions, which are repeated irregularly and the content of which changes depending on many factors that are not always amenable to accurate accounting, are established using a photograph of the working day or the method of momentary observations.

The identified manufacturing processes are carefully described and the characteristics are included in the memory of personal computers. The design of a new product is carried out on personal computers, circuits are entered into machine memory. The computer technologically designs the manufacturing process of all parts, determines the most rational processing methods, and also determines the quality requirements of the products. The technological design is approved by the technical council, then the technological process is automatically disassembled with the simultaneous calculation of the labor intensity according to the existing standards.

The Modapts Plus system (Modular Arrangement of Predetermined Time Standards) belongs to the third generation of trace element standards. Its feature is the use of enlarged 
elements, as a result of which its application is greatly simplified. This system is used today in the automotive, apparel and medical industries.

The Work Factor system is also widely used, that is, a system that takes into account work factors. It differs from the named ones in that it sets the standards for microelements separately for the main and additional movements, depending on the number of work factors taken into account.

Despite the widespread use of microelement rationing, foreign firms do not refuse to carry out time-based monitoring of the rationing of certain types of special work. In foreign practice, the forms of linear programming, multivariate regression analysis, and statistical methods for studying time expenditures are standardized and widespread. This methodological and material-technical base allows enterprises to create norms for almost all categories of workers.

In the process of computational and analytical standardization, the possibilities of combining operations, rearranging elements of the main and auxiliary work, or creating complex operations are identified. This achieves a reduction in the cost of standardized time. It is impossible to enact an industry standard immediately without its mastering by workers within a certain period of time as the output of the product increases. In this case, it is necessary to apply increasing development rates to the industry standard of time.

The modern system of labor rationing can be attributed to a mathematical model of a specific job to determine the period of work and other parameters necessary for labor rationing, the method of mathematical modeling of standardized jobs obtained through practical control. This fact shows that the system of mathematical modeling can be attributed to the analytical method of rationing, since without practical control over the expenditure of working time, the use of such a system in practice is impossible.

It should also be recognized that most of them are in some way subjective, as they are based on hypotheses, similarities, inferences, as well as human factors.

Obviously, modern computer technology allows avoiding a number of problems that have arisen due to fatigue, lack of attention or insufficient qualifications of controllers. But achieving $100 \%$ accuracy can change dramatically under the influence of various external and internal factors.

However, foreign specialists in modern conditions allow corporations to save thousands of dollars a year, preventing the competent use of modern methods of labor rationing, efficient use of economic and financial resources, economic unjustified staff reduction and unreasonable costs of purchasing equipment. At the same time, some researchers, despite significant achievements in the industry under study, explain that the reason for the unfavorable state of the American economy is insufficient attention to general industrial engineering, as well as to labor standards on the part of the state.

In industrialized countries, the place of quality management and business processes in organizational transformations has become widespread. Therefore, from our point of view, considering labor rationing as a process, it is advisable to link the labor rationing system with the optimization of business processes at enterprises.

Optimization of a business process is associated with setting a time, quantitative framework for the implementation of this process, which will directly be the standardization of this process.

Business process improvement is one of the most popular management tools and business performance improvement. At the same time, methods for improving business processes are considered within the framework of certain approaches.

Improving business processes within these approaches is performed using a number of methods:

1. fast solution analysis (FAST) technique;

2. benchmarking the process; 
3. process reengineering;

4. overall quality management;

5. theory of limiting systems;

6. lean manufacturing.

The Rapid Solution Analysis (FAST) technique is a three-month process improvement over a specific process. This methodology is based on quickly identifying ways to improve the process in a group meeting that lasts two to three days. Typical improvements to the FAST technique are cost and cycle time savings. As a result of using the FAST method, economic indicators can be improved by $5-15 \%$.

Process benchmarking is based on a comparative analysis of the enterprise's business processes with reference processes of other companies performing a similar type of activity. The main purpose of benchmarking is to identify the reasons for the better functioning of business processes, as well as improve the current business processes of the organization in which the study is being conducted. Benchmarking can reduce costs, cycle times and error rates by $20-50 \%$.

Business Process Reengineering (BPR) is a fundamental rethinking and radical redesign of business processes to achieve significant improvements in such key performance indicators for modern business as costs, quality, service level and responsiveness. The founders of this technique are M. Hammer and J. Champi.

Total quality management or TQM (Total Quality Management) is an organization-wide method of continuously improving the quality of all organizational processes. The main goal of TQM is the systematic achievement of the tasks set by the enterprise through continuous improvement of work. The TQM technique consists of two mechanisms:

- quality control (Quality Assurance; QA) - maintaining the required quality level;

- quality improvement (Quality Improvements; QI) - the existing level of quality must not only be maintained, but also continuously improved.

The founder of this method is E. Deming, who represents the continuous improvement of the quality of business processes in the form of a cycle. The Deming cycle (PDCA cycle) is a circle of quality, that is, continuous work that aims to improve the process, as well as optimize all objects and units.

The theory of limiting systems is aimed at identifying and eliminating a weak point in the organization's activities that limits the company's growth opportunities, as well as its effective functioning.

Lean manufacturing is an enterprise management concept, the main task of which is to eliminate all types of losses in the production process.

All approaches to improving business processes have their own strengths and weaknesses. The choice of these approaches depends on the specifics of the enterprise and the ultimate goal of improvement.

An in-depth look at the development of working time regulation shows that in connection with the reorganization of business processes and production processes, discussions and conflicts have arisen related to the flexibility of working hours.

The regulation and organization of working hours have always been very important for trade unions. Since their inception, they have fought to raise wages and improve the working and living conditions of their members. An important area of activity of trade unions is labor standards applied in different sectors.

In light of the increasing opportunities for organizing working hours, it is not surprising that flexible working time models are expanding, as well as opportunities for evening, night and weekend work. The lines between paid work and free time are becoming increasingly blurred. And more and more often, the agility strategies pursued by companies conflict with the needs of employees for working hours. 
Discussions on programs and collective agreements within trade unions show that workers' organizations are not afraid to face new challenges in working time policies. An exemplary survey shows that unions in the services sector as well as in other sectors have taken steps towards new and forward-looking working time policies.

Unions are doing more than just keeping demanding new working time policies. Through polls, protests and organized strikes, they have been able to mobilize their members, reinforce their demands and draft collective agreements to improve the organization of labor standards.

The above exemplary references to approaches to the programmatic and practical reorientation of trade union policy of working hours, not to mention the current disputes regarding the regulation and organization of working hours, are far from over. But they serve as a reminder that working time policy remains a controversial issue.

In addition to trade unions and workers 'representation bodies, influential players in this area also include company management, employers' associations and government agencies (governments, labor inspectorates).

A study by the European Foundation for the Improvement of Living and Working Conditions research on the evolution and regulation of working time has identified four different systems of regulation of working time:

1. Legislative - the state plays a dominant role in regulating working hours. Legal regulations apply to most workers; Collective agreements and collective agreements concerning working hours or the organization of working hours are rare in this system.

2. Legislative with the addition to the collective agreement - this system is dominated by the government's activities in regulating working hours. However, legal provisions are often supplemented by collective agreements. This leads to the establishment of rules that are generally more favorable to workers than legal regulations. Additional collective bargaining agreements are held at the industry or corporate level.

3. Regulation of working hours only by collective agreements - standards are mainly determined by collective agreements, usually at the industry level. However, they can be further supplemented by agreements on the organization of working hours at the company level. In this case, standards for the duration, organization and location of working hours are usually the result of collective agreements between employers and trade unions.

4. Unilateral regulation of working time - legislation does not play a large role in setting working time norms, existing collective bargaining structures are highly decentralized. The length and organization of working hours are usually specified in individual employment contracts and generally reflect the conditions set and proposed by employers.

Working hours are almost exclusively regulated by law and are established in eight EU countries (Bulgaria, Estonia, Latvia, Lithuania, Hungary, Poland, Romania and Slovenia). Labor law not only regulates standard working hours and work organization, but also contains specific rules for specific jobs or categories of workers.

In Greece, France, Portugal and Slovakia, working hours are regulated by law. In addition, unions are negotiating at sectoral and corporate levels to ensure better working hours for workers. Legislation is also the most important institutional level in the Czech Republic, Ireland and Malta for setting working time standards, but unlike the member states mentioned above, adjustments arising from collective agreements are mainly carried out at the company level.

In another third of EU countries, legislation is still relevant for setting working time standards, but it only establishes a general framework for organizing working time at the industry or corporate level. The predominant institutional level of collective agreements in these cases is the sectoral level. Employers and trade unions negotiate here and agree on the organization of working hours. 
Industry agreements are often complemented by company-level agreements. This also applies to the Scandinavian countries (Denmark, Finland, Norway and Sweden), where there is a long tradition of regulating working hours through collective agreements. This also applies to Austria, Belgium, Germany, Italy, Cyprus, the Netherlands and Spain, where the regulation of working hours is mainly carried out at the industrial level.

In contrast, the UK is the only country where unilateral labor regulation prevails. Working hours, work schedules and organization of working hours are established by management for almost two thirds of workplaces. At the sectoral and corporate level, collective bargaining agreements only play a role in a few sectors, such as manufacturing or construction.

Labor standards in European countries have not decreased significantly over the past two decades, but have become more diversified and more flexible. This development poses new challenges for trade unions. They have responded by adapting their collective bargaining policy. As a result of the harmonization of new and innovative rules for the development and implementation of working time models and labor standards, workers in most European countries now have a wide range of options for organizing their working time.

\section{Results and discussions}

By introducing labor safety and environmental management systems at the enterprise, the management team primarily aims at identifying and reducing the main types of risks of negative impact of production activities and manufactured products on the environment, health of employees, population and consumers.

By implementing systems of labor safety, organization of working hours and environmental management, the business receives the following benefits. Considering the size of the wage bill, for large enterprises this is significant funds, but even for relatively small organizations with a small number of employees, this is a significant savings.

A rough analysis of the new rules for organizing working time shows that significant progress has been made in the programmatic reorientation of trade union policy in the field of working time. However, this goal has not yet been fully achieved, there is a gap between the demands of the trade unions and everyday operational life that needs to be bridged.

At this stage in the development of modern society in Russia, trade unions have lost most of their direct functions due to the fact that their activities have become limited by the Labor Code of the Russian Federation. In this regard, the number of trade unions has significantly decreased in comparison with the Soviet period. In the Russian Federation, there is a sufficient legal and methodological basis for the definition and establishment of labor standards. Partially such a base has been preserved in the CIS countries. However, only recommendations for the development of labor standards are established by law. Therefore, all work on the development and improvement of labor standards falls on enterprises.

In the legislation of Western, industrially developed countries, there are no recommendations for the development and even the very concept of labor standards. Business by default organizes its work with maximum efficiency and social orientation towards human capital. And all controversial issues are resolved with the participation of trade union organizations.

Thus, we can say that for Western, industrially developed countries, labor rationing is the main element in the formation of a system of employee motivation. Statistics show that the use of reasonable rates, together with an effective incentive system, can increase productivity by up to $25 \%$. It is the rationing of labor that may indicate that minor changes 
in the composition of work and a reduction in time spent on non-production needs can affect the overall efficiency of the enterprise.

\section{Conclusion}

The issues of environmental protection and rational use of natural resources are relevant and significant in modern conditions, since the welfare of society, the development of industry and the state of health of the population directly depend on them. Since there are serious shortcomings in the use of the natural resource potential of the Russian Federation, the issues of environmental management are especially acute.

The philosophy of environmental management allows not only to form an understanding of the personnel at the enterprise about environmental approaches to managing production processes and reducing environmental pollution, but also to create tools that allow regulating environmental processes from economic and social positions. Thus, environmental management systems are necessary for the harmonious development of any organization and make it possible to optimally restructure production processes in order to generate additional profits and reduce costs.

Another element of this system is the labor rationing. For Western, industrially developed countries, labor rationing is the main element in the formation of a system of employee motivation. Statistics show that the use of reasonable rates, together with an effective incentive system, can increase productivity by up to $25 \%$. It is the rationing of labor that may indicate that minor changes in the composition of work and a reduction in time spent on non-production needs can affect the overall efficiency of the enterprise.

\section{References}

1. K.D. Byatova, The role of environmental accounting and audit in global sustainable development, Proceedings of the conferences of the Research Center Sociosphere 9, 810 (2020)

2. K.A. Denisov, The strategy of sustainable development of industrial enterprises on an innovative basis as a factor in ensuring the ecological safety of the region $(\mathrm{SPb}$.: Publishing house of SPbGEU, 2019)

3. L.N. Orlova, Environmental management in the practice of economic activity of economic structures, Waste and resources 7, 2, 5 (2020)

4. R.S. Stirmanov, Management of stakeholders in the environmental management system, Scientific electronic journal Meridian 15 (49), 54-56 (2020)

5. Ye.G. Khorovinnikova, Organizatsiya upravleniya ekonomicheskimi protsessami predpriyatiya $v$ oblasti ekologicheskogo menedzhmenta, Vestnik yevraziyskoy nauki 12, 2, 77 (2020)

6. N.Yu. Shipilov, Ekologicheskiy menedzhment: strategicheskiy aspect, Aktual'nyye problemy ekonomiki i menedzhmenta 1 (25), 184-190 (2020)

7. Ye.V. Val', Sistema oplaty truda na osnove ekonomicheskikh pokazateley, Spravochnik kadrovika 1, 39-44 (2015)

8. A.F. Nosov, Sushchnost' zarabotnoy platy i faktory yeye formiruyushchiye, Ekonomist 4, 11-19 (2015) 